\title{
Administración legal y fáctica: revisión de dos supuestos problemáticos en Derecho Penal
}

\author{
María Soledad Gil Nobajas \\ Doctora Europea. Profesora de Derecho Penal \\ Universidad de Deusto
}

Recibido: 20.05.2011

Aceptado: 31.05 .2011

\begin{abstract}
Resumen: Mayoritariamente la doctrina y jurisprudencia penal acuden a una interpretación material del concepto de administrador de hecho, sobre la base del ejercicio efectivo y real de las funciones atribuidas al administrador y sin necesidad de que exista un nombramiento habilitante. A pesar de la equiparación del administrador designado formalmente y del administrador fáctico a efectos penales, se presentarían en la praxis societaria algunos supuestos dudosos, de cuya calificación como administrador de hecho o de derecho dependerá el que pueda atribuírseles responsabilidad penal por la comisión de determinados delitos especiales. En este trabajo se analizan dos de estos casos: el representante de la persona jurídica administradora y el administrador oculto, tomando en esta última hipótesis el ejemplo de los grupos de sociedades.
\end{abstract}

Palabras clave: Responsabilidad penal, Persona jurídica, Administrador de hecho, Sociedad matriz

Abstract: Mainly, criminal legal practice and theory defend a material interpretation of the concept of de facto administrator on the basis of an effective and real exercise of his functions, without need of a qualifying appointment. Despite the matching of the administrator formally appointed and de facto administrator under criminal law, in the corporate practice there are some doubtful situations, on whose qualification as an administrator of fact or Law may depend the attribution of criminal liability for the commision of certain special offences. In this paper two of these cases will be analyzed: the representative of the administrator-legal person, and the hidden administrator, taking into account in the latter case the example of the groups of undertakings.

Key Words: Criminal liability, Legal person, De facto administrator, Parent company

Sumario: I. PUNTO DE PARTIDA. Una interpretación material del concepto de administrador de hecho. II. PRIMER SUPUESTO. El representante de la persona jurídica administradora. III. SEGUNDO SUPUESTO. El administrador oculto. En concreto, el administrador de la sociedad matriz. IV. BIBLIOGRAFÍA. 


\section{PUNTO DE PARTIDA. Una interpretación material del concepto de administrador de hecho}

El Código penal de 1995 incorporó la figura del administrador de hecho junto al administrador de derecho en el marco de los delitos societarios y en el ámbito de aplicación de la cláusula del actuar en lugar de otro del art. 31 CP. Sin perjuicio de los delitos comunes que obviamente pueden cometer, esto significa que ambos son reconocidos como sujetos activos en dos grupos de delitos especiales. A grandes rasgos, el diferente significado de la incriminación específica del administrador en el campo de los delitos societarios y del art. $31 \mathrm{CP}$ residiría en el hecho de que el cumplimiento de los deberes cuya infracción condiciona la realización del tipo penal corresponde personalmente al propio administrador o, por el contrario, es un cumplimiento con carácter derivado, puesto que inicialmente correspondería a la propia persona jurídica. Así, por ejemplo, cuando el administrador comete una administración desleal porque ha garantizado unas deudas personales con bienes de la sociedad, infringe sus deberes de diligencia, fidelidad y lealtad societaria consagrados en los arts. 225 a 232 LSC. Pero si se le imputa un delito fiscal por haber defraudado a la administración tributaria en concepto de impuesto de sociedades, se le responsabiliza por aplicación del art. 31 porque ha asumido derivadamente el cumplimiento del deber de tributar que originariamente corresponde a la propia persona jurídica. Como puede apreciarse esta diferencia que se acaba de señalar está planteada a los efectos que ahora interesan de la atribución de responsabilidad al administrador y deja de lado en este trabajo la cuestión de por sí conflictiva de la responsabilidad penal de la persona jurídica, introducida en el Derecho penal español por medio de la LO 5/2010, de 22 de junio, de reforma del Código penal.

Pero volviendo al tema del administrador societario, sería contrario a los principios de culpabilidad y de responsabilidad por el hecho propio pretender hacerle penalmente responsable por el mero dato de haber infringido el deber que, originaria o derivadamente, estaba en sus mano cumplimentar; o dicho de otra forma, responsabilizarle por el mero hecho de ostentar una determinada posición jurídica en la persona jurídica, aunque ciertamente la más importante por la asunción de las funciones de gestión y representación que implica. Con ello se quiere poner de relieve dos cuestiones que considero fundamentales en la debatida cuestión del concepto penal de administrador de hecho, pero igualmente en relación con el administrador legalmente designado. En realidad podría decirse que las consideraciones que van a servir de punto de partida al análisis de los dos supuestos problemáticos que vertebran este trabajo, vendrían a ofrecer un resumen de la discusión doctrinal y una toma de postura en este tema, cuyo trasfondo no es posible reflejar con la profundidad y rigor que requeriría en estas líneas.

En primer lugar, mayoritariamente la doctrina interpretan el concepto de administrador de hecho en clave material, de manera que el criterio delimitador estaría en la relación del sujeto con el bien jurídico, es decir, en la exis- 
tencia de una posición de dominio sobre la posibilidad de lesión del bien jurídico, que a su vez se concreta en el ejercicio real y efectivo de las funciones propias del administrador ${ }^{1}$. Esta corriente interpretativa, que también es mayoritaria en la jurisprudencia ${ }^{2}$, permite ampliar la noción puramente mercantilista de la administración fáctica, en la que únicamente podrían incluirse los casos de irregularidades en algunos de los elementos esenciales para adquirir la condición de administrador de iure -nombramiento, aceptación y, para algunos autores, inscripción en el registro- y los supuestos de caducidad del cargo. Bajo una visión material del término, más adecuada a la finalidad protectora de bienes jurídicos que persigue el Derecho penal, se abre la puerta a la posible responsabilidad de otras situaciones de ejercicio fáctico de las atri-

${ }^{1}$ La interpretación material del concepto de administrador de hecho por la que se trata de fundamentar la equivalencia de su actuación con la del administrador de derecho parte en origen de la tesis del dominio social típico desarrollada por GRACIA MARTÍN. Conforme a este planteamiento, la condición de sujeto activo no proviene del estatus formal requerido para el desempeño de la función de administración, sino de la posibilidad de dominio que tiene el agente sobre la vulnerabilidad del bien jurídico, es decir, de su capacidad real para lesionarlo con independencia de la vinculación formal con la entidad. Quien posee, de iure, el estatus de administrador ostenta, por definición, el dominio social típico que, en todo caso, deberá comprobarse en el caso concreto; quien carece de esa cualidad formal, pero ejerce de hecho la actividad correspondiente a la función de administrador, también puede llegar a ser sujeto activo del tipo, puesto que actúa dentro del ámbito de protección de la norma, ejerciendo el dominio típico sobre el bien jurídico y asumiendo, en consecuencia, una posición de garante. El centro de gravedad recae, así, en la relación material, efectiva y real del sujeto con el bien jurídico penalmente protegido por el tipo. Sobre esta concepción, en profundidad, vid. GRACIA MARTÍN, L., El actuar en lugar de otro en Derecho Penal.I. Teoría General, Universidad de Zaragoza, 1985, pp. 338-339 y 350 y ss.

${ }^{2}$ Es representativa, en este sentido, la STS, $2^{\text {a }}$, 59/2007, de 26 de enero, en cuya virtud "será administrador de hecho quien sin ostentar formalmente la condición de administrador de la sociedad, ejerza poderes de decisión de la sociedad y concretando en él los poderes de un administrador de derecho. Es la persona que, en realidad manda en la empresa, ejerciendo los actos de administración, de obligación de la empresa, aunque formalmente sean realizadas por otra persona que figura como su administrador (...). Por tanto, en la concepción de administrador de hecho no ha de estarse a la formalización del nombramiento, de acuerdo a la respectiva modalidad societaria, ni a la jerarquía en el entramado social, sino a la realización efectiva de funciones de administración, del poder de decisión de la sociedad, la realización material de funciones de dirección. Son muchas las situaciones que pueden plantearse, normalmente referidas a apoderados para obligar a la sociedad, y será la concurrencia de una dirección real de la sociedad la que marque el sujeto activo del delito, en este caso, como destinatario de un deber especial de cumplir la exigencia de veracidad en la presentación anual de las cuentas de la sociedad". Por su parte, la STS, 2a , 1949/2000, de 18 de diciembre 2000 , califica al administrador de hecho de "dominador de hecho". También postulan un concepto material de administrador de hecho las SSTS, $2^{\text {a }}, 1116 / 1999$, de 16 de julio; 2476/2001, de 26 de diciembre; 1027/2003, de 14 de julio; 816/2006, de 26 de julio; 1101/2007, de 27 de diciembre. 
buciones que corresponden al administrador societario, incluso en los supuestos en los que simplemente no hay una habilitación legal al sujeto. Con todo tampoco puede decirse que exista una postura unánime dentro de esta corriente hermenéutica, puesto que ante el temor de desvirtuar la naturaleza de los delitos que incriminan al administrador de hecho y de derecho, de delitos especiales a delitos comunes, algunos autores introducirían algún tipo de correctivo formal al concepto material de administrador de hecho, exigiendo una mínima apariencia formal, en el sentido de un consentimiento tácito de la sociedad o la exteriorización de las funciones de administración ${ }^{3}$.

El panorama doctrinal se completa con la tesis de los delitos de infracción de deber, que ofrece una combinación del criterio formal y material a la hora de delimitar conceptualmente la administración fáctica, en función de la estructura del tipo penal implicado. En realidad, se está aquí, en su versión más extrema, ante una construcción dogmática sobre el fundamento del injusto penal, de manera que debe diferenciarse entre delitos especiales de dominio y delitos de infracción de deber. En los primeros la responsabilidad surge por competencia de organización, es decir, porque el sujeto no se ha organizado correctamente y, en consecuencia, ha causado un daño a tercero. En los segundos, la responsabilidad surge por la infracción de un determinado deber extrapenal que incumbe al sujeto, esto es, responsabilidad institucional del sujeto, puesto que el sujeto se encuentra previamente obligado institucionalmente a la garantía y tutela del bien jurídico. En este tipo de delitos resulta indiferente que el sujeto desempeñe fácticamente función alguna, ya que lo que

\footnotetext{
${ }^{3}$ Asumen un concepto material de administrador de hecho con un mínimo de apariencia formal de que se es administrador, FARALDO CABANA, P., Los delitos societarios, Tirant lo Blanch, Valencia, 1996, p. 148; LA MISMA, El delito societario de falsedad en documentos sociales, Tirant lo Blanch, Valencia, 2003, pp. 79-80; CASTRO MORENO, A., El delito societario de administración desleal, Marcial Pons, Madrid, 1998, p. 238; DEL ROSAL BLASCO, B., Los delitos societarios en el Código Penal de 1995, Tirant lo Blanch, Valencia, 1998, p. 64; POLO VEREDA, J., «Delitos societarios: reflexiones para una selección de aspectos polémicos», en La Ley, 1998-2, p. 2046; RODRÍGUEZ MOURULLO, G.: «Delitos contra los derechos de los socios y delitos de obstrucción», en AA. VV.: El nuevo Código Penal y los delitos societarios, Fundación Caixa Galicia, 1998, p. 232; NÚÑEZ CASTAÑO, E., Responsabilidad de la empresa, Tirant lo Blanch, Valencia, 2000, pp. 97-98; MARTÍNEZ RUÍZ, J., La tutela jurídico-penal de las potestades administrativas de supervisión o inspección de los mercados financieros. El art. 294 del Código Penal, Marcial Pons, MadridBarcelona, 2001, pp. 534-535 y 566; PÉREZ VALERO, I., El delito societario de falsedad en las cuentas anuales (art. 290 CP), Tirant lo Blanch, Valencia, 2001, p. 300; DÍAZ-MAROTO Y VILLAREJO, J.POLO VEREDA, J., Problemas generales de aplicación de los delitos societarios, Centro de Estudios Ramón Areces, Madrid, 2002, pp. 65-66; BAJO, M./BACIGALUPO, S., Derecho Penal Económico, 2a ed., Centro de Estudios Ramón Areces, Madrid, 2010, p. 122.
} 
importa es la infracción del deber especial que le incumbe desde una posición altamente formalizada ${ }^{4}$.

Al margen de las concretas objeciones dogmáticas que pueden achacarse a cada una de las tesis expuestas, creo que debe defenderse un concepto de administración fáctica no limitado, a priori, por ningún deber extrapenal, ni por ningún requisito de consentimiento o tolerancia de la sociedad. A mi juicio, las únicas notas válidas al respecto deben venir dadas por el acceso a la posición material de dominio y ejercicio de las funciones de administrador, según señala la teoría del dominio social típico, y que colocan al administrador de hecho en una posición de garante respecto de la vulnerabilidad del bien jurídico idéntica a la que ostenta el administrador de derecho. Con otras palabras, la delimitación conceptual del administrador fáctico integra dos niveles. A un primer nivel abstracto corresponde exclusivamente dar respuesta al porqué de la equiparación incriminatoria del administrador de iure y de facto, definido por la idea de dominio, cuestión que es ajena al tipo penal específico que se aplique. La limitación de la responsabilidad penal a la figura del administrador fáctico debe provenir, por tanto, de un segundo nivel, un estadio de concreción que ha de solventarse en sede de tipicidad. Sólo así tiene sentido excluir algunas modalidades de administración fáctica cuando la lesión del bien jurídico exige una alta cualificación normativa ligada a la condición jurídica del sujeto. Dicha restricción debe someterse a juicio en cada caso particular, relacionando al agente con la conducta típica y el objeto material del tipo penal. En definitiva, no se trata de un problema sobre la validez penal del concepto de administrador de hecho, sino de subsunción típica. O, si se prefiere, de interpretación teleológica de un concepto abierto a la luz del delito aplicable ${ }^{5}$. Sin duda habrá supuestos en los que será imposible que el

${ }^{4}$ Vid., por todos, GARCÍA CAVERO, P., La responsabilidad penal del administrador de hecho en la empresa: criterios de atribución, Montecorvo, Madrid, 1999, p. 146, 177 y 197; EL MISMO, «Otra vez sobre la responsabilidad sobre la responsabilidad penal del administrador de hecho: una cuestión general y otra particular», InDret, 3/2006, <www.indret.com>, pp. 6 y 7, requiriendo, en todo caso, el requisito de la apariencia formal de cara al exterior. Para una exposición detallada de la tesis de los delitos de infracción de deber y sus réditos en el ámbito del Derecho penal empresarial, vid. BACIGALUPO SAGESSE, S.: Autoría y participación en delitos de infracción de deber. Una investigación aplicable al Derecho penal de los negocios, Marcial Pons, Madrid, 2007.

${ }^{5}$ Asume un concepto de administrador de hecho, con base en un criterio fáctico, restringido en sede de tipicidad, GÓMEZ BENÍTEZ, J.M., «Delitos societarios», en AA. VV.: Derecho Penal Económico, CGPJ, Madrid, 2001, p. 581. Siguen también esta concepción, GALLEGO SOLER, J-I., «El concepto de administrador de hecho como criterio de imputación de la autoría en Derecho Penal», en CORCOY BIDASOLO, M., Derecho Penal de la Empresa, Universidad Pública de Navarra, Pamplona, 2002, pp. 160-162 y 166; FERNÁNDEZ BAUTISTA, S., El administrador de hecho y de derecho. Aproximación a los delitos con restricciones con sede de autoría, Tirant lo Blanch, Valencia, 2007, pp. 315-316 y 325. 
agente realice el tipo sin una determinada cualificación subjetiva, pero esta cuestión habrá que resolverse en relación con "el" tipo concreto que requiera un elemento normativo de autoría y "la" específica situación fáctica de la que se parta.

En segundo lugar, consecuencia directa de la toma de postura anterior se desprende también que si el criterio definidor de una administración fáctica reside en la idea de dominio o ejercicio real y efectivo de las atribuciones que corresponden al administrador, aunque no exista nombramiento habilitante, también al administrador de derecho, que ya posee el estatus jurídico requerido para asumir dichas funciones, debe exigírsele el desempeño real de estas para fundamentar su responsabilidad penal en los delitos especiales en los que originaria o derivadamente es reconocido como sujeto activo del tipo. Retomando las palabras con las que se han iniciado este trabajo, únicamente de esta forma es posible conjugar adecuadamente la equivalencia de la actuación del administrador de hecho y de derecho con los principios fundamentales del Derecho penal de culpabilidad y responsabilidad por el hecho.

A la luz de estas consideraciones, se propone seguidamente una revisión de dos supuestos de dudosa calificación entre las categorías de administrador de derecho y de hecho: el representante de la persona jurídica designada administrador de otra persona jurídica y el caso de la administración oculta, analizada con el ejemplo de la figura grupal. Ahora bien, es necesario advertir que los dos supuestos que se van a analizar se sitúan en el plano del problema referido al primer nivel de definición descrito en torno al concepto de administrador de hecho, algo que todavía no prejuzga si por el concreto hecho realizado se va a derivar responsabilidad penal o no.

\section{PRIMER SUPUESTO. EI representante de la persona jurídica admi- nistradora}

La legislación mercantil admite plenamente que una persona jurídica adquiera la condición de administradora de otra persona jurídica. Aunque la LSC no contiene una norma explícita al respecto ${ }^{6}$, el RRM dispone expresamente que en caso de administrador persona jurídica, no procederá la inscripción del nombramiento en tanto no conste la identidad de la persona física que aquélla haya designado como representante suyo para el ejercicio de las funciones propias del cargo. En consecuencia, no parece discutible que si legal-

${ }^{6} \mathrm{El}$ art. 231.2 LSC recoge una autorización indirecta a esta posibilidad cuando hace una enumeración de las personas vinculadas a la persona jurídica administradora a efectos de delimitar el deber de lealtad de los administradores. 
mente una persona jurídica puede administrar a otra persona jurídica, es la propia entidad ostenta la posición de administrador de derecho a todos los efectos ${ }^{7}$.

No son pocas las dudas que esta cuestión suscita en sede civil y penal. Pero desde la perspectiva del Derecho Penal que sustenta este trabajo, la posibilidad de designar a una persona jurídica administradora de otra conlleva importantes consecuencias de cara a la atribución de la responsabilidad penal, puesto que originariamente la sociedad administradora es la que posee las especiales características de autoría que requiere el tipo penal que entre en consideración, si se trata de un delito especial. Hasta la entrada en vigor de la LO 5/2010 la situación desembocaba, como es sabido, en la impunidad de la propia persona jurídica, a salvo, claro está, de lo dispuesto en el art. $31 \mathrm{CP}$ sobre la cláusula del actuar en lugar de otro. Pero con la reforma penal y la introducción del art. 31 bis también la persona jurídica puede ser penalmente responsable, bajo las condiciones que establece la nueva regulación y en determinados supuestos tasados legalmente. Con todo, hay que hacer dos apreciaciones. Primera, la responsabilidad penal de la persona jurídica que incorpora la reforma se somete a un sistema de numerus clausus en el que no tienen cabida, precisamente, ni los delitos societarios, ni el nuevo art. 282 bis relativo a la estafa de inversiones, a pesar de que en ellos se incrimina la actuación del administrador de hecho y de derecho. Además, el art. 31 bis permite una responsabilidad concurrente entre la persona jurídica y la persona física ${ }^{8}$, por lo que a efectos de la atribución de la responsabilidad penal a esta última sigue siendo necesario constatar que ha cometido un delito y comprobar si su actuación es subsumible dentro del concepto de administrador de hecho o de derecho.

En atención a esta cuestión, la doctrina ha buscado la solución acudiendo a lo dispuesto en el art. 143 RRM. El Reglamento exige que se designe, con carácter previo, un representante permanente de la sociedad

\footnotetext{
${ }^{7}$ De esta misma opinión RODRÍGUEZ MONTAÑÉS, T., La responsabilidad penal del administrador desleal y los nuevos delitos societarios, McGraw-Hill, Madrid, 1997; CASTRO MORENO, A., El delito societario ..., ob. Cit., p. 229; GÓMEZ BENÍTEZ, J.M., Curso de Derecho Penal de los negocios a través de casos. Reflexiones sobre el desorden legal, Colex, Madrid, 2001, GALLEGO SOLER, J-I., «El concepto de administrador de hecho...», ob. cit., p. 171; p. 101; MARTÍNEZ-BUJÁN PÉREZ, C., Derecho Penal Económico y de la Empresa. Parte Especial, $3^{\text {a }}$ ed., Tirant lo Blanch, Valencia, 2011, p. 351.

${ }^{8} \mathrm{El}$ apartado segundo del art. 31 bis recoge la regla general de la responsabilidad concurrente entre la persona jurídica y la persona física, entre ellas, el administrador de hecho o de derecho. Eso no es óbice para que este mismo precepto señale determinadas excepciones a la responsabilidad concurrente que autorizan la sanción autónoma de la persona jurídica que, a efectos prácticos, tienen visos de convertirse en la regla general.
} 
administradora ${ }^{9}$. En orden a la designación, la sociedad administradora cuenta con absoluta libertad e independencia respecto de la entidad administrada, de manera que, en principio, sólo está obligada a ponerlo en conocimiento de esta última, pero no a aceptar imposiciones ni condicionamientos que mermen su libertad de elección. Como regla general, la entidad elegirá a su representante entre aquellas personas que obtengan su plena confianza y reúnan los requisitos de capacidad exigidos por el Derecho, ya sea un administrador de la persona jurídica administradora o un apoderado a tales efectos. En todo caso, una vez designado ejercerá las facultades propias de todo administrador en la sociedad administrada, es decir, las funciones de gestión y representación con plenitud de derechos y sin más limitaciones que las que establezcan las leyes o los estatutos. La pregunta es, por tanto, si la persona física representante puede y debe ser calificada de administrador y, de ser así, si se trata de un administrador de derecho o de hecho.

Para algunos autores el representante permanente de la sociedad administradora es un auténtico administrador de derecho, ya que las personas jurídicas siempre actuarían a través de sus órganos y, en este caso, la actuación del representante habría de considerarse como la actuación de la propia persona jurídica administradora ${ }^{10}$. Otros autores coinciden inicialmente con esta

${ }^{9}$ La exigencia de que se designe un representante de la entidad administradora ha suscitado entre los autores si el nombramiento debe referirse a una única persona física o cabría la posibilidad de nombrar dos o más representantes. Del art. 143 RRM parece que se veda esta segunda opción, aunque nada obsta a que pueda designarse un sustituto del representante. No obstante, la doctrina opina que de la Ley y la jurisprudencia no se desprende una exclusión concluyente, por lo que cabría pensar la posibilidad que se designaran dos o más representantes, del mismo modo en que el art. 124 RRM permite que el órgano de administración pueda optar entre diversas modalidades de configuración. A este respecto, aunque mostrando ciertas dudas para alguna de las modalidades, PRADA GONZÁLEZ, J.M., «La persona jurídica administradora de una sociedad anónima», en Homenaje al Profesor Aurelio Menéndez, tomo II, Civitas, Madrid, 1996, pp. 2321-2323.

${ }^{10}$ CASTRO MORENO, A., El delito societario..., ob. cit., pp. 229-230. También de esta opinión GÓMEZ BENÍTEZ, J.M., Curso ..., ob. cit., p. 101, si bien para este autor deberían en realidad considerarse administradores indirectos de derecho, pues en puridad el auténtico administrador de derecho es la persona jurídica administradora.

Para estos autores la calificación de administrador de derecho es ajena a la aplicación de la cláusula del actuar en lugar de otro del art. $31 \mathrm{CP}$ a los delitos societarios, que sería absolutamente inoperativa en este ámbito. Vid. GÓMEZ BENÍTEZ, J.M., «Administradores de hecho y de derecho en el nuevo Código Penal», en EL MISMO, Estudios penales, Colex, Madrid, 2001, p. 162, EL MISMO, Curso..., ob. cit., p. 112, refiriéndose expresamente al supuesto de que el administrador de derecho es una persona jurídica. Niega también la operatividad del art. $31 \mathrm{CP}$ a los delitos societarios, SEQUEROS SAZATORNIL, F., Delitos societarios y conductas afines. La responsabilidad penal y civil de la sociedad, sus socios y administradores, $2^{\mathrm{a}}$ ed., La Ley, Madrid, 2006, p. 584. No obstante, otra corriente doctrinal llega a la misma conclusión de que el representante es administrador de derecho, vía aplicación del art. $31 \mathrm{CP}$ en relación con la persona jurídica administradora, con carácter previo a la reforma por LO 5/2010. Así, MORENO CÁNOVES, A./RUÍZ MARCO, F., Delitos so- 
postura, pero admiten que el representante pueda ser calificado también de administrador de hecho, cuando la entidad que administra se encuentra en una situación anómala -liquidación, constitución, etc.- o cuando se trata de un simple apoderado de la sociedad administradora y no de su administrador de derecho ${ }^{11}-$. Y, en fin, otra corriente prefiere calificar al representante de administrador de hecho ${ }^{12}$ de la sociedad administrada, pues solo la entidad administradora posee de iure dicha condición. Según esto, en la medida en que la persona física que realmente desempeña las funciones de gestión y representación ostenta el dominio social típico y asume una posición de garante respecto de bienes jurídicos, puede decirse que ejerce, de facto, la labor de administración.

Por mi parte, considero perfectamente admisible esta última postura, dado que realmente la administración de iure corresponde a la persona jurídica administradora, y siempre y cuando se establezca la correspondiente conexión de este supuesto de administración fáctica con el objeto material y conducta del tipo penal que entre en consideración. Sin embargo, a mi juicio es posible un diferente planteamiento de esta hipótesis, cuya explicación requiere deslindar varias situaciones. Para calificar jurídico-penalmente al representante de la sociedad administradora, considero que debe atenderse, por un lado al título por el que el sujeto accede a dicha representación y, por otro, tomar en consideración las diferentes competencias atribuidas legalmente a los admi-

cioeconómicos, EDIJOS, Zaragoza, 1996, p. 254; RODRÍGUEZ MONTAÑÉS, T., La responsabilidad penal..., ob . cit., p. 120; MARTÍNEZ-BUJÁN PÉREZ, C., Derecho Penal Económico y de la Empresa. Parte Especial..., ob. cit., p. 351. Lo que no especifican estos autores es si el art. $31 \mathrm{CP}$ opera con carácter general en el ámbito de los delitos societarios o únicamente en el supuesto puntual de una persona jurídica administradora. Por su parte, FARALDO CABANA da por supuesta la aplicación del art. $31 \mathrm{CP}$ en los delitos societarios cuando hay persona jurídica administradora, pero lo que no especifica la autora es si el representante es responsable de la comisión del delito societario como administrador de hecho o de derecho. En FARALDO CABANA, P., El delito societario..., ob. cit., p. 125.

${ }^{11}$ MORENO CÁNOVES, A./RUÍZ MARCO, F., Delitos socioeconómicos..., ob. cit., p. 254; RODRÍGUEZ MONTAÑÉS, T., La responsabilidad penal ..., ob. cit., p. 120; CASTRO MORENO, A.: El delito societario..., ob. cit., p. 230, nota 122; RÍOS CORBACHO, J.M., El administrador de hecho en los delitos societarios, Universidad de Cádiz, 2005, p. 151; MAGRO SERVET, V., «La responsabilidad penal de los administradores de hecho», en SOLER PASCUAL, L.A. (Dir.), Responsabilidad de las personas jurídicas en los delitos económicos, CDJ, CGPJ, Madrid, 2006, p. 150; MARTÍNEZ-BUJÁN PÉREZ, C., Derecho Penal Económico y de la Empresa. Parte Especial..., ob. cit., p. 351.

${ }^{12}$ SÁNCHEZ ÁLVAREZ, M.M., Los delitos societarios, Aranzadi, Pamplona, 1996, pp. 60-61; DEL ROSAL BLASCO, B., Los delitos societarios..., ob. cit., p. 72; FERRÉ OLIVÉ, J.C., «Sujetos responsables en los delitos societarios», en Revista Penal, 1998-1, pp. 21-29; p. 25; MEINI, I., Responsabilidad penal del empresario por los hechos cometidos por sus subordinado, Tirant lo Blanch, Valencia, 2003, pp. 420-457; RÍOS CORBACHO, J.M., El administrador de hecho..., ob. cit., p. 58, aunque no queda claro si estos autores llegan a esta conclusión por aplicación o no del art. 31 CP. 
nistradores. Partiendo de estas premisas, tal vez se llegue a la conclusión de que el representante de la persona jurídica administradora puede ser sujeto activo idóneo de ilícitos penales cometidos en la persona jurídica administrada, pero bajo una calificación diferente ${ }^{13}$, según los supuestos. Intentaré, a continuación, fundamentar coherentemente esta hipótesis.

Conviene aclarar previamente el supuesto de hecho debatido, bastante frecuente, a la sazón, en la práctica societaria: la sociedad X nombra administrador -supongamos que un miembro más de su Consejo de Administración- a la sociedad Y. Esta última sociedad, a su vez, está administrada por su propio Consejo de Administración que ejercita las funciones de gestión y representación de la sociedad Y. Aquí sitúa la doctrina mayoritaria los términos de la discusión, sin mayores precisiones. Puesto que en el fondo, se dice, quien realmente va a llevar a cabo la administración de la sociedad $\mathrm{X}$ va a ser el propio Consejo de Administración de la sociedad Y, el miembro de este que se designe como representante será, en primer lugar, administrador de derecho de la sociedad Y; pero también, en segundo lugar, administrador de hecho o de derecho, según la preferencia de cada autor, de la sociedad X. Pero, a mi modo de ver, calificar al representante de administrador de hecho o de derecho presupone afirmar que esta persona realmente es administradora de la sociedad Y, propuesta que no puede ser asumida automáticamente. No parece discutible que la sociedad $\mathrm{Y}$ es administradora de derecho de la sociedad X, pues esta posibilidad viene reconocida legalmente. También por imperativo legal la sociedad $\mathrm{Y}$ ha de desempeñar la función de administración por medio de una persona física. Llegado a este punto, las dudas surgen a la hora de interpretar el art. 143 RRM, que se refiere a la persona física que aquella (la sociedad administradora, en el caso propuesto, la sociedad Y) haya designado como representante suyo para el ejercicio de las funciones propias del cargo. Señala FERNÁNDEZ TERUELO que hay que diferenciar al que actúa como administrador de la sociedad de aquel que representa a la sociedad administradora ${ }^{14}$, lo que, según entiendo, sugiere que no necesariamente el representante designado por la sociedad $\mathrm{Y}$ tiene que ser un miembro de su Consejo de Administración, sino un representante de la sociedad Y en la sociedad X o, lo que viene a ser lo mismo, un representante voluntario de la sociedad Y que ejerce labores de administración en la sociedad X. De esto se desprende una

${ }^{13}$ Con esto hago referencia a la calificación por la que el representante se erige en sujeto idóneo del tipo penal, aspecto que es totalmente ajeno al título de imputación por el que deba responder y, por cierto, independiente de la responsabilidad penal en que pueda concurrir la propia persona jurídica por la vía del art. 31 bis. En otras palabras, a efectos penológicos corresponde la misma pena al representante -bien como autor, bien como partícipe-, tanto si se le considere administrador de derecho, de hecho o representante voluntario de la entidad, criterio también recogido en el art. $31 \mathrm{CP}$.

${ }^{14}$ En Los delitos societarios en el Código Penal español, Dykinson, Madrid, 1998, p. 97. 
primera conclusión provisional en los supuestos en los que la persona física designada no es, a su vez, administradora de derecho de la persona jurídica: respecto de los ilícitos penales que el representante comete en la sociedad X en relación con los deberes de administración de la sociedad Y en cuya representación actúa, vendría en aplicación la cláusula del art. $31 \mathrm{CP}$. Aunque la especial cualidad de autoría requerida por el tipo penal se trasladaría a la persona física, no en función de su posición como administrador de hecho o de derecho, sino como representante voluntario de otro, criterio de atribución también recogido en el art. $31^{15}$. Fuera de este supuesto, cuando la persona física designada es, igualmente, administradora de la persona jurídica, se estaría ante un supuesto de administrador fáctica.

Sin perjuicio de lo anterior, aún es necesario introducir otras variables en esta cuestión. Las funciones de gestión y representación atribuidas, ex lege, a los administradores, en cualquiera de las modalidades que contempla la legislación societaria, pueden ser delegadas con el límite expreso del art. 249.2 LSC. En su virtud, la rendición de cuentas y la presentación de balances son, en todo caso, indelegables. Dado que estas labores indelegables corresponden a la vertiente de gestión societaria, sólo pueden ejercerse por quien, además de ser nombrado representante de la sociedad Y, es a su vez administrador en esa misma sociedad. En estos casos, esto excluye la posibilidad de acceder a la representación en virtud de un título diferente al de administrador. En consecuencia, es posible hablar de administrador de hecho en dos supuestos: primero, con carácter general, cuando un administrador de la sociedad Y es designado representante en la sociedad X. Segundo, concretamente esta calificación será obligatoria cuando se trata de funciones indelegables del Consejo de Administración, pero por aplicación del art. $31 \mathrm{CP}$. En cambio, cuando el representante accede a este cargo bajo un título diferente, puede ser sujeto activo del tipo penal cometido en la sociedad $X$ únicamente en aquello que sea delegable -funciones de representación de la entidad y actos de gestión que no se refieran a la formulación de cuentas y balances- $y$, en este caso, gracias al criterio de "representante voluntario de otro" previsto en el art. 31 CP.

Recapitulando. El art. $31 \mathrm{CP}$ no es aplicable, por regla general, al ámbito de los delitos societarios, ya que en ellos las condiciones para ser sujeto ac-

\footnotetext{
${ }^{15}$ Esta interpretación es posible si se admite que este criterio de atribución remite tanto a personas físicas como jurídicas, a lo cual no veo inconveniente. Admite este planteamiento, aunque concluye que el representante sería como mínimo un administrador de hecho FERNÁNDEZ TERUELO, J.G., Los delitos societarios..., ob. cit., p. 97 (sin cursiva en el original). En la misma línea, GALLEGO SOLER, J-I., «El concepto de administrador de hecho...», ob. cit., p. 171. Contraria a esta interpretación, FARALDO CABANA, para quien la expresión "de otro" sólo se refiere a la persona física. En El delito societario..., ob. cit., p. 126, nota 317.
} 
tivo apuntan, directamente, a los administradores de hecho o de derecho ${ }^{16}$. No obstante, existe una excepción a la regla, exclusivamente en el supuesto de que una persona jurídica es nombrada administradora de derecho de otra persona jurídica, pues entonces es necesario aplicar el precepto en cuestión para transferir al representante designado las especiales condiciones de autoría que exige el tipo penal, con independencia de que se trate de algún delito en los que expresamente se prevé la responsabilidad penal de la persona jurídica por la vía del art. 31 bis. Dentro de este supuesto puntual, dicho representante podrá responder penalmente conforme a dos calificaciones diferentes: como administrador de hecho, supuesto más frecuente, cuando el representante de la entidad administradora sea, a su vez, miembro de su Consejo de Administración; o como representante voluntario, cuando el sujeto que accede a la representación no ostenta este cargo de administrador en la sociedad administradora, aunque aquí sus funciones de administración en la sociedad administrada deberán ceñirse exclusivamente a aquellas que tengan carácter delegable ${ }^{17}$.

\section{SEGUNDO SUPUESTO. El administrador oculto. En concreto, el ad- ministrador de la sociedad matriz}

En numerosos supuestos de administración fáctica el sujeto que concentra el poder decisorio en la entidad ni tiene nombramiento habilitante, ni asume las facultades del cargo de administrador desde otra posición jurídica legitimadora, como ocurre en ocasiones con el otorgamiento de poderes a un

\footnotetext{
${ }^{16}$ No comparto la afirmación de RÍOS CORBACHO de que la regla del art. 31 resulta superflua en relación con los delitos societarios (El administrador de hecho..., ob. cit., p. 59). Decir que es una regla superflua significa que ya estaría contenida en los propios delitos societarios, con lo que la cláusula general del art. 31 CP supondría una reiteración innecesaria en estos casos. En realidad no es una regla superflua para los delitos societarios, sino que el art. 31 trata de resolver un problema que no se plantea en estos delitos, porque no hay escisión entre el sujeto cualificado -administrador de hecho o de derecho- y realización del tipo. La única excepción constituye el supuesto estudiado de que una persona jurídica haya sido designada administradora de otra persona jurídica.

${ }^{17}$ Se podría preguntar si esta misma solución es aplicable a los apoderados, dado que estos son también representantes voluntarios de la persona jurídica. Sin embargo, no parece posible acudir a esta interpretación, porque no existiría escisión entre destinatario primario de la norma y sujeto idóneo del delito. Es decir, en los apoderamientos, el sujeto se encuentra directamente vinculado por el deber que le otorga el poder, mientras que, en el supuesto que ahora se analiza, entre la sociedad administrada y el representante voluntario se interpone la entidad administradora, que, de manera primaria, tiene que respetar la obligación que le impone el tipo penal. Por eso, los casos de apoderamiento sólo pueden resolverse por la vía del administrador de hecho, cuando existe dominio sobre la estructura social típica y siempre y cuando esté en condiciones de llevar a cabo la conducta típica.
} 
sujeto por parte del administrador legal ${ }^{18}$. En realidad, las situaciones que ahora se abordan implican la existencia de un determinado vínculo con la sociedad, pero por diversas razones se considera preferible mantener oculto. De ahí que estos supuestos se denominen de "administradores ocultos" o "administradores en la sombra", es decir, sujetos que dirigen los designios de la entidad a su antojo manteniendo su actuación encubierta. Ahora bien, es muy difícil que en la práctica se dé una administración de estas características en estado puro, ya que de cara a la sociedad y a terceros siempre debe aparecer un administrador regular, aunque su actuación se someta a las directrices del administrador oculto. Por tanto, el primer elemento definidor de esta clase de administración fáctica es la concurrencia de dos sujetos: el administrador de derecho o, al menos, con visos de regularidad, que aparece formalmente de cara a la sociedad y a terceros y el "hombre de atrás", que materialmente decide los designios de la entidad.

Los motivos que generan una situación de administración oculta son de muy diversa índole ${ }^{19}$ y alcanzan diferentes grados de implicación ${ }^{20}$, pero en modo alguno son un fenómeno excepcional. Es muy habitual que entre la sociedad y su verdadero centro de poder medien uno o más eslabones intermedios, con el objeto principal de poner cuerpo y voz a las instrucciones que provienen del sujeto que actúa en la sombra. La trascendencia jurídico-penal de una actuación delictiva cometida bajo estos parámetros centra el debate en

${ }^{18}$ Estas situaciones de administración fáctica se presentan con frecuencia ante los tribunales y suelen ser habituales en las sociedades de corte familiar. En estas entidades, la administración fáctica se presenta entre padres e hijos o entre cónyuges, donde, por lo general, existen razones basadas en la relación de parentesco para esperar que el miembro de la familia -normalmente los hijos o la esposa- va a cumplir con las instrucciones del administrador oculto que se presenta de cara a terceros bajo otro título. Sobre los posibles supuestos que integra, con alusiones jurisprudenciales, puede consultarse PERDICES HUETOS, A., «El concepto de administrador de hecho como criterio de imputación de la autoría en Derecho mercantil», en CORCOY BIDASOLO, M.: Derecho Penal de la Empresa, Universidad Pública de Navarra, Pamplona, 2002, pp. 142-143.

${ }^{19}$ Eludir las responsabilidades que derivan de la condición de administrador, utilizar a una persona en situación de apuros económicos o, simplemente, el hecho de que una persona poderosa quiera manejar los entresijos sociales desde una cómoda posición encubierta, como la de un socio mayoritario o un acreedor privilegiado.

${ }^{20}$ Desde el punto de vista del alcance de la responsabilidad penal de ambos sujetos, debe diferenciarse los casos en los que el administrador formal carece de autonomía decisoria, quedando su actuación plenamente sometida a los dictados del administrador oculto, de aquellos otros en los que existe una coadministración porque también el administrador formal mantiene una esfera de actuación propia. Como puede advertirse esta cuestión excede las pretensiones de este trabajo, en el que se aborda exclusivamente si la persona en la sombra es administradora de hecho y, en consecuencia, puede ser sujeto idóneo de ilícitos penales, pues remite a la aplicación de las reglas de autoría y participación penales, con los específicos problemas que plantean en el marco de estructuras organizativas. 
la calificación que merece el hombre de atrás, puesto que el alcance de su responsabilidad penal diferirá en función de la postura que se adopte. Para su análisis, y dada la variedad de supuestos en que puede materializarse la administración oculta, se centrará la atención en los grupos de sociedades, a los que juzgo buenos exponentes de las características y problemas penales que plantea esta vertiente de la administración fáctica.

A pesar de ser un fenómeno reconocido por el Derecho, los grupos de sociedades constituyen una materia controvertida y escasamente regulada. No existe una noción unitaria de lo que es la figura grupal, ni hay una ley específica que la regule. Esto se debe a que su creación es puramente fáctica, por lo que únicamente es posible encontrar preceptos puntuales que se refieran a ella. De estas escasas referencias legales, la doctrina mercantilista define mayoritariamente el grupo de sociedades como la situación de varios empresarios -generalmente sociedades- jurídicamente independientes que, por estar sometidos a una dirección única de contenido general, constituyen una unidad económica ${ }^{21}$. De acuerdo con esta noción, son dos las notas esenciales del grupo: 1. Desde una perspectiva jurídica, cada sociedad que integra el grupo mantiene su propia autonomía, de manera que globalmente no posee una personalidad jurídica independiente. 2. Económicamente, sin embargo, los intereses sociales individuales de las sociedades se someten al interés del grupo, atribuyendo a la sociedad dominante o matriz el ejercicio de la dirección del grupo. Independencia jurídica y dirección unitaria, elementos en principio antagónicos, se articulan mediante el control. Puede decirse que existen tantos tipos de grupos como modos de adquirir el control $^{22}$, bien mediante técnicas societarias, bien por medio de contratos empresariales. Pero lo importante, en definitiva, no es tanto el modo en que se adquiere el control, sino el hecho de establecer una relación de subordinación y dominio. Con otras palabras, si el objetivo es establecer una dirección económica efectiva y estable, es necesario que la sociedad dominante tenga el poder de influir, de manera decisiva y duradera, en la gestión de las sociedades dominadas ${ }^{23}$ En esta cuestión re-

${ }^{21}$ DUQUE DOMÍNGUEZ, J.F., «Concepto y significado institucional de los grupos de empresas», en Libro-Homenaje a Ramón $M^{a}$ Roca Sastre, vol. III, Junta de Decano de los Colegios Notariales, Madrid, 1977, p. 532; EMBID IRUJO, J.M., Grupos de sociedades y accionistas minoritarios: la tutela de la minoría en situaciones de dependencia societaria y grupo, Ministerio de Justicia, Madrid, 1987, p. 25.

${ }^{22}$ Grupos por subordinación o por coordinación, centralizados o descentralizados, contractuales o de hecho, etc. Vid. una exposición de la tipología de grupos en DUQUE DOMÍNGUEZ, J.F., «Concepto y significado...», ob. cit., pp. 539-549.

${ }^{23}$ SÁNCHEZ ÁLVAREZ, M.M., «Grupos de sociedades y responsabilidad de los administradores», en $R D M, 1998$-I, p. 127. No obstante, dirección económica unitaria y control son dos términos de difícil delimitación y con riesgo de solaparse e, incluso, confundirse. A este respecto, se discute si el presupuesto básico de los grupos de sociedades está en la nota de control, puesto que este elemento permite alcanzar la dirección unitaria, o en el aspecto de la dirección unitaria. Con todo tampoco resultan claros los contornos de este último concepto, 
viste especial importancia el contenido del artículo 42 CCo, relativo a la obligación de formular cuentas consolidadas, en cuya virtud se presume la relación de dominio y, en consecuencia, la existencia de grupo cuando una entidad mercantil posee respecto de otra la mayoría de los derechos de voto. Esta participación mayoritaria ha podido surgir, bien porque la entidad posee la mayoría de los derechos de voto por sí misma o por acuerdos con otros socios -participación directa-, bien porque los derechos corresponden a sociedades dominadas o a personas que actúan por su cuenta -participación indirecta-. Asimismo, también habrá indicios de la existencia de control cuando una sociedad esté facultada para nombrar o destituir a la mayoría de los miembros del órgano de administración o pueda nombrar exclusivamente con sus votos a la mayoría de miembros ${ }^{24}$.

Es indudable que la utilización de estos mecanismos otorga a los administradores de la sociedad dominante una capacidad real y efectiva para condicionar la actuación de los órganos sociales de las sociedades dominadas, a pesar de que, por definición, estas mantengan su propia organización y sus órganos de administración conserven formalmente las competencias. Todo ello queda mediatizado desde el momento en que existe una dirección unitaria del grupo $^{25}$. Eso no implica que el grupo sea, por sí mismo, un factor de fraude o

llegando a sostenerse que consiste en el poder de dirección de la empresa o sociedad domi nante sobre las sociedades dependientes. Vid. una aproximación a esta controversia en SÁNCHEZ ÁLVAREZ, M.M., «Grupos de sociedades...», ob. cit., pp. 123-136. No obstante, coincido con la mayoría de la doctrina en que el presupuesto fundamental para hablar de grupo es la idea de la dirección unitaria, ya que el fenómeno grupal presenta una gran variedad de tipos, pudiendo existir aunque no se dé el sometimiento de unas sociedades respecto a otras, esto es, los llamados grupos paritarios o por coordinación.

${ }^{24}$ Una corriente doctrinal entiende que el art. 42 CCo no regula de forma adecuada las notas esenciales del concepto de grupo porque deja de lado la existencia de una dirección unitaria del conjunto de sociedades. Conforme a esta opinión, se recogería una noción acorde a la esencia de grupo en el art. 4 de la Ley 24/88, de 26 de julio, del Mercado de Valores, en virtud del cual, a los efectos de esta ley, se considerarán pertenecientes a un mismo grupo las entidades que constituyan una unidad de decisión, porque alguna de ellas ostente o pueda ostentar, directa o indirectamente, el control de las demás, o porque dicho control corresponda a una o varias personas físicas que actúen sistemáticamente en concierto. Este artículo continúa diciendo que se presumirá que existe en todo caso unidad de decisión cuando concurra alguno de los supuestos contemplados en el número 1 del artículo 42 del Código de Comercio, o cuando al menos la mitad más uno de los Consejeros de la dominada sean Consejeros o altos directivos de la dominante, o de otra dominada por ésta. En este sentido, el art. 4 LMV adopta un concepto más amplio de grupo frente al del art. 42 CCo, caracterizado por dos factores: un control que puede alcanzarse por cualquier medio, tanto societario como contractual, y la existencia de una unidad de decisión. Sobre la controversia en torno al concepto de grupo, vid. SÁNCHEZ ÁLVAREZ, M.M., «Grupos de sociedades...», ob. cit., pp. 128-135; FERNÁNDEZ MARKAIDA, I., Los grupos de sociedades como forma de organización empresarial, Edersa, Madrid, 2001, pp. 218-227 y 260-268.

${ }^{25}$ DUQUE DOMÍNGUEZ, J.F., «Concepto y significado...», ob. cit., p. 569. 
riesgo ${ }^{26}$, pero nada impide que gracias a su estructura y conexiones internas pueda ser también fuente de ilícitos penales. Lo que caracteriza a estos delitos es, precisamente, que la actuación del órgano de administración de la sociedad dominada, si bien es atribuible formalmente a sus miembros, depende del órgano de administración de la sociedad dominante, de forma exclusiva o en connivencia con aquellos. Imagínese, por ejemplo, que, siguiendo la política del grupo, la sociedad dominante impone a una o varias filiales su descapitalización en beneficio de otras, dando lugar a una quiebra fraudulenta; o que se disponga fraudulentamente de los bienes de la sociedad dominada en beneficio de la sociedad dominante o de otras; e igualmente cabe pensar en unas falsedades en documentos sociales como mecanismo para llevar a cabo las actuaciones anteriores.

La vía adecuada para dar una respuesta jurídico-penalmente válida, a mi juicio, a estas situaciones delictivas consiste en incluir a los administradores de la sociedad dominante dentro del concepto general de administrador de hecho ${ }^{27}$ y darles, así, entrada en el ámbito del sujeto activo de los tipos penales que requieren la condición de administrador de hecho o de derecho para ser autor del mismo. La decisión, ya sea en sí misma constitutiva de delito, ya determine la realización posterior del hecho delictivo, se discute y adopta directamente en el Consejo de Administración de la sociedad dominante y después se traslada formalmente al órgano de administración de la sociedad dominada, normalmente a través de las mismas personas integradas en ambos consejos, así como a su Junta General ${ }^{28}$.

No obstante, esta postura entra en colisión con ciertas interpretaciones material de administrador de hecho que limitan el ejercicio efectivo de las atribuciones de administración sobre la base del dominio social típico a la

\footnotetext{
${ }^{26}$ En principio, la subordinación de una o varias entidades a otra es valorativamente neutra o, incluso, beneficiosa, por cuanto que con su creación se pretende beneficiar al conjunto de las sociedades que lo integran, es decir, el interés del grupo, a efectos de optimizar sus recursos, reducir costes y repartir riesgos y responsabilidades.

${ }^{27}$ Los administradores de la sociedad dominante no son administradores de derecho de la sociedad dominada, debido a la independencia jurídica que mantiene cada sociedad y ello a pesar de que pueda coincidir en el mismo sujeto la condición de administrador en el órgano de administración de las sociedades madre y filial. GÓMEZ BENÍTEZ, J.M., Curso..., ob. cit., p. 102. También califica de administradores de hecho a los administradores de la sociedad madre respecto de sus filiales, MEINI, I., Responsabilidad penal del empresario..., ob. cit., p. 458; SEQUEROS SAZATORNIL, F., Delitos societarios..., ob. cit., p. 77. El Tribunal Supremo acoge un concepto material de administrador de hecho favorable a la inclusión del administrador oculto. Así, la STS, 2a , 816/2006, de 26 de julio, califica de administrador de hecho "a toda persona que por sí sola o conjuntamente con otras, adopta e impone las decisiones de la gestión de una sociedad, y concretamente los expresados en los tipos penales, quien de hecho manda o gobierna desde la sombra".
}

${ }^{28}$ GÓMEZ BENÍTEZ, J.M., Curso ..., ob. cit., p. 104. 
existencia de un mínimo formal en su situación. Conforme a esta corriente interpretativa, aunque el sujeto que se mantiene en las sombras domina y controla el hecho típico, se arroga unas funciones que no se materializan externamente y, por tanto, no pueden ser reconocidas, ni siquiera de forma tácita, por la sociedad. En consecuencia, dicen estos autores, los casos de grupos de sociedades y, en general, todos aquellos supuestos en los que el sujeto que ostenta el poder decisorio de la sociedad actúa por medio de una persona o personas interpuestas -físicas o jurídicas-, no caen dentro de la interpretación penal de lo que es un administrador de hecho. Puesto que ya existe un administrador formalmente nombrado, que es quien ostenta la posición jurídica para ser sujeto idóneo del tipo penal, la finalidad protectora de bienes jurídicos del Derecho Penal quedaría cubierta responsabilizando a este último a título de autor; por su parte, el administrador oculto únicamente puede responder conforme a las reglas de la participación por su contribución al hecho, porque es un extraneus vetado a la autoría ${ }^{29}$.

No cabe duda de que una interpretación restrictiva del concepto de administración fáctica tiene una finalidad claramente garantista, al objeto de que no se responsabilice penalmente a un sujeto que carece de la cualidad formal legalmente exigida por el tipo penal aplicable. Sin embargo, a mi juicio no creo que deba ser esta la orientación, ya que sí creo posible atribuir al hombre de atrás o administrador oculto la condición que requieren algunos tipos penales especiales para ser sujeto idóneo de los mismos. Esta condición no es ciertamente la de administrador de derecho, pero sí la de administrador de hecho. Desde postulados político-criminales y de justicia material, es sumamente discutible que quien realmente toma las decisiones, tiene el dominio sobre el administrador nombrado o, en el mejor de los casos, lo comparte con este y controla los medios y formas de la comisión del hecho haya de tener un trato más privilegiado que el administrador que aparece como tal de cara a la sociedad y a terceros, por el hecho -de por sí dudoso- de no exteriorizar su actuación ${ }^{30}$. Una visión estricta de este escenario favorecería la impunidad

${ }^{29}$ Esta sería la consecuencia lógica de excluir a tales sujetos del concepto de administrador de hecho, ya que los delitos societarios y los delitos en los que entra en aplicación el art. $31 \mathrm{CP}$ son delitos especiales y, además, propios. La única excepción la encontraría GÓMEZ BENÍTEZ en el art. $290 \mathrm{CP}$, al que califica de delito especial impropio. En este caso, los extrane $i$-personas que no sean administradores de hecho o de derecho pero puedan falsificar documentos sociales, especialmente los externos- también podrían responder penalmente como autores, pero únicamente respecto del correspondiente delito común. No obstante, respecto de los administradores de las sociedades dominantes, se muestra favorable a englobarlos dentro del concepto de administrador de hecho, de tal modo que sea posible su consideración como autores de la mayoría de los delitos societarios -y del ámbito de aplicación del art. $31 \mathrm{CP}$, me permito añadir- exclusivamente o en conjunción con los administradores de derecho. En «Delitos societarios», ob. cit., p. 578, nota 22.

${ }^{30}$ NÚÑEZ CASTAÑO, E., Responsabilidad de la empresa ..., ob. cit., p. 138. 
del hombre de atrás en este tipo de conductas, sobre todo en situaciones en las que el administrador regular actúa bajo error, coacción o miedo.

En mi opinión el criterio rector de la equivalencia entre la actuación del administrador de iure y de facto no debe recaer en un aspecto de naturaleza formal, sino en la asunción del dominio social o desempeño real y efectivo de las funciones propias del cargo de administrador; en el caso específico de los grupos de sociedades, en la efectiva dirección de la entidad filial por parte del administrador de la sociedad dominante o, en términos generales, por cualquier administrador oculto, que le coloca en situación de poder vulnerar el bien jurídico tutelado. El administrador que formalmente aparece de cara al exterior viene a ser, en numerosas ocasiones, una simple marioneta del sujeto en las sombras, por lo que decir que únicamente es partícipe por su intervención en el delito cometido por el administrador de derecho parece una burla a la realidad. Por supuesto, no es posible colegir de aquí una máxima general de atribución de la responsabilidad penal a ambos sujetos, ya que las hipótesis que se pueden presentar en la praxis societaria recorren todo un abanico de posibilidades. El administrador de derecho puede ser el testaferro u hombre de paja del administrador oculto. Otras veces, en cambio, el administrador regular o aparente mantiene un grado de autonomía decisoria o, incluso, actúa en connivencia con el hombre de atrás. Ello afectará a la atribución de la responsabilidad penal de ambas figuras jurídicas -a título de autoría o de participación-, dependiendo del grado de dominio que manifiesten en su actuación, pero no así a su calificación de administrador de derecho y de hecho ${ }^{31}$.

De lo expuesto se desprende que al objeto de incluir la administración oculta en un concepto de administración fáctica con pretensiones de validez penal, o bien se niega cualquier tipo de requisito formal como presupuesto para la presencia de una administración de hecho, o bien se interpreta de una manera compatible con la esencia de la administración oculta. De acuerdo con una interpretación material del concepto de administrador de hecho, según la tesis del dominio social, considero más conveniente decantarse por la primera opción ${ }^{32}$, puesto que interpreto que las limitaciones a esta noción deben

${ }^{31}$ Consideran al administrador oculto como administrador de hecho, SÁNCHEZ ÁLVAREZ, M.M., Los delitos societarios..., ob. cit., p. 63; FERRÉ OLIVÉ, J.C., «Sujetos responsables en los delitos societarios», en Revista Penal, 1998-1, p. 27; SILVA SÁNCHEZ, J.M., «El "actuar en lugar de otro" en el nuevo Código Penal español», en EL MISMO, Consideraciones sobre la teoría del delito, Ad-Hoc, Buenos Aires, 1998, p. 208; NÚÑEZ CASTAÑO, E., Responsabilidad penal ..., ob. cit., p. 138; GÓMEZ BENÍTEZ, J.M., Curso ..., ob. cit., pp. 104 y 109; CORCOY BIDASOLO, M., Manual práctico de Derecho Penal. Parte Especial. Tomo II. Derecho Penal de la empresa, Tirant lo Blanch, Valencia, 2002, p. 177; GALLEGO SOLER, J-I., «El concepto de administrador de hecho...», ob. cit., pp. 168 y 171.

${ }^{32}$ Opción que defiende NÚÑ̃Z CASTAÑO, E., Responsabilidad penal..., ob. cit., p. 138. Parece desprenderse esta opinión en SILVA SÁNCHEZ, J.M.: «El "actuar en lugar de otro"...», ob. cit., p. 202; EL MISMO, El nuevo escenario del delito fiscal en España, Atelier, Barcelona, 2005pp. 23-24. 
realizarse en sede de tipicidad, es decir contrastando las concretas funciones de administración que lleva a cabo el sujeto con el objeto material y la conducta típica que determina el tipo penal. Con todo, todavía podría interpretase que la presencia de un posible elemento de carácter formal, si no directamente, se manifiesta a través del testaferro, que es quien exterioriza la actuación del administrador oculto. Pero la nota de la exteriorización recae sobre la función de administración, no sobre la persona que la ejercita. Por tanto, los efectos externos de la gestión son independientes de que sea el administrador, personal y directamente o por medio de un hombre de paja o tercero, quien los ejercite $^{33}$. Además, difícilmente puede decirse en un grupo de sociedades que la situación no es conocida por la sociedad filial, es decir, que no existe un mínimo de reconocimiento social tal y como entienden otros autores, ya que precisamente lo característico de este fenómeno es que la Junta General y el Consejo de Administración de la sociedad dominada están participados mayoritariamente por los administradores de la sociedad dominante y se encuentran subordinados a sus directrices.

Para finalizar, es preciso efectuar algunas matizaciones. En relación con los grupos de sociedades se admite por la doctrina mercantilista, aunque con ciertas reservas, que es suficiente un control potencial sobre las sociedades dependientes para la existencia del grupo. Sin embargo, a efectos penales, no parece de recibo admitir una mera posibilidad hipotética de ejercer el control para dar por cumplido el acceso al dominio social, sino que dicho control debe ser real y efectivo. Sin este dominio material sobre la estructura típica no se justifica la responsabilidad penal del agente y en modo alguno puede presuponerse cuando el control o influencia es meramente potencial. Corolario de lo anterior, y para todo supuesto de administración mediante persona interpuesta, la subordinación o dependencia ha de suponer un sometimiento o acatamiento a la dirección del administrador oculto. Con otras palabras, no basta para calificar al hombre de atrás de administrador de hecho el mero asesoramiento o consejo profesional; por el contrario, el control requiere una entidad suficiente y cierta regularidad en el tiempo para que permita al agente acceder a la vulnerabilidad del bien jurídico protegido y asumir una posición de garante, lo que habrá de comprobarse en el caso concreto en función de la propia actuación llevada a cabo por el sujeto que actúa en la sombra.

\section{BIBLIOGRAFÍA.}

Bacigalupo Sagesse, S., Autoría y participación en delitos de infracción de deber. Una investigación aplicable al Derecho penal de los negocios, Marcial Pons, Madrid, 2007.

\footnotetext{
${ }^{33}$ GALLEGO SOLER, J-I., «El concepto de administrador de hecho...», ob. cit., pp. 167168.
} 
Bajo, M./Bacigalupo, S., Derecho Penal Económico, $2^{\mathrm{a}}$ ed, Centro de Estudios Ramón Areces, Madrid, 2010.

Castro Moreno, A., El delito societario de administración desleal, Marcial Pons, Madrid, 1998.

Corcoy Bidasolo, M., Derecho Penal de la Empresa, Universidad Pública de Navarra, Pamplona, 2002.

Del Rosal Blasco, B., Los delitos societarios en el Código Penal de 1995, Tirant lo Blanch, Valencia, 1998.

Díaz-Maroto y Villarejo, J./Polo Vereda, J.: Problemas generales de aplicación de los delitos societarios, Centro de Estudios Ramón Areces, Madrid, 2002.

DuQue DomíngueZ, J.F., «Concepto y significado institucional de los grupos de empresas», en Libro-Homenaje a Ramón $M^{a}$ Roca Sastre, vol. III, Junta de Decanos de los Colegios Notariales, Madrid, 1977, pp. 525-586.

EMBID IRUJo, J.M., Grupos de sociedades y accionistas minoritarios: la tutela de la minoría en situaciones de dependencia societaria y grupo, Ministerio de Justicia, Madrid, 1987.

Faraldo Cabana, P., El delito societario de falsedad en documentos sociales, Tirant lo Blanch, Valencia, 2003.

-Los delitos societarios, Tirant lo Blanch, Valencia, 1996.

FERnÁNDEZ BAutista, S., El administrador de hecho y de derecho. Aproximación a los delitos con restricciones con sede de autoría, Tirant lo Blanch, Valencia, 2007.

FERNÁNDEZ MARKAIDA, I., Los grupos de sociedades como forma de organización empresarial, Edersa, Madrid, 2001.

Fernández Teruelo, J.G., Los delitos societarios en el Código Penal español, Dykinson, Madrid, 1998.

FERRÉ Olivé, J.C., «Sujetos responsables en los delitos societarios», en Revista Penal, 1998-1, pp. 21-29.

GALLEGo SOLER, J-I., «El concepto de administrador de hecho como criterio de imputación de la autoría en Derecho Penal», en CORCOY BIDASOLO, M., Derecho Penal de la Empresa, Universidad Pública de Navarra, Pamplona, 2002, pp. 147-175.

GARCía CAVERO, P., «Otra vez sobre la responsabilidad sobre la responsabilidad penal del administrador de hecho: una cuestión general y otra particular», InDret, 3/2006, www.indret.com

- La responsabilidad penal del administrador de hecho en la empresa: criterios de atribución, Montecorvo, Madrid, 1999.

Gómez Benítez, J.M., «Administradores de hecho y de derecho en el nuevo Código Penal», en EL MISMO, Estudios penales, Colex, Madrid, 2001, pp. 161-165.

- Curso de Derecho Penal de los negocios a través de casos. Reflexiones sobre el desorden legal, Colex, Madrid, 2001. 
— «Delitos societarios», en AA. VV.: Derecho Penal Económico, CGPJ, Madrid, 2001, pp. 563-622.

Gracia Martín, L., El actuar en lugar de otro en Derecho Penal. I. Teoría General, Universidad de Zaragoza, 1985.

Magro Servet, V., «La responsabilidad penal de los administradores de hecho», en SOLER PASCUAL, L.A. (Dir.), Responsabilidad de las personas jurídicas en los delitos económicos, CDJ, CGPJ, Madrid, 2006, pp. 133-186.

MARTínez Ruíz, J., La tutela jurídico-penal de las potestades administrativas de supervisión o inspección de los mercados financieros. El art. $294 \mathrm{del}$ Código Penal, Marcial Pons, Madrid-Barcelona, 2001.

Martínez-Buján Pérez, C., Derecho Penal Económico y de la Empresa. Parte Especial, $3^{\mathrm{a}}$ ed., Tirant lo Blanch, Valencia, 2011.

MeInI, I., Responsabilidad penal del empresario por los hechos cometidos por sus subordinado, Tirant lo Blanch, Valencia, 2003.

Moreno CÁnoves, A./Ruíz Marco, F., Delitos socioeconómicos, EDIJOS, Zaragoza, 1996.

NúÑEz Castaño, E., Responsabilidad de la empresa, Tirant lo Blanch, Valencia, 2000.

Perdices Huetos, A., «El concepto de administrador de hecho como criterio de imputación de la autoría en Derecho mercantil», en CORCOY BIDASOLO, M.: Derecho Penal de la Empresa, Universidad Pública de Navarra, Pamplona, 2002, pp. 131-146.

Pérez VAlero, I., El delito societario de falsedad en las cuentas anuales (art. 290 CP), Tirant lo Blanch, Valencia, 2001.

Polo Vereda, J., «Delitos societarios: reflexiones para una selección de aspectos polémicos», en La Ley, 1998-2, pp. 2044-2056.

Prada GonZÁlez, J.M., «La persona jurídica administradora de una sociedad anónima», en Homenaje al Profesor Aurelio Menéndez, tomo II, Civitas, Madrid, 1996, pp. 2295-2338.

Ríos Corbacho, J.M., El administrador de hecho en los delitos societarios, Universidad de Cádiz, 2005.

RodRíGUEZ MONTAÑÉs, T., La responsabilidad penal del administrador desleal y los nuevos delitos societarios, McGraw-Hill, Madrid, 1997.

RodríGuez Mourullo, G.: «Delitos contra los derechos de los socios y delitos de obstrucción», en AA. VV.: El nuevo Código Penal y los delitos societarios, Fundación Caixa Galicia, 1998.

SÁNCHEZ Álvarez, M.M., «Grupos de sociedades y responsabilidad de los administradores», en Revista de Derecho Mercantil, 1998-I, pp. 117-153. - Los delitos societarios, Aranzadi, Pamplona, 1996.

Sequeros Sazatornil, F., Delitos societarios y conductas afines. La responsabilidad penal y civil de la sociedad, sus socios y administradores, $2^{\mathrm{a}}$ ed., La Ley, Madrid, 2006. 
SiLva SÁnchez, J.M.: El nuevo escenario del delito fiscal en España, Atelier, Barcelona, 2005

- «El "actuar en lugar de otro" en el nuevo Código Penal español», en EL MISMO, Consideraciones sobre la teoría del delito, Ad-Hoc, Buenos Aires, 1998, pp. 175-220. 